\title{
Putting the Pieces Together: \\ Assessing Social, Ecological, and \\ Economic Rangeland Sustainability
}

\author{
By Kristie A. Maczko, Larry D. Bryant, Dennis W. Thompson, \\ and Steven J. Borchard
}

\section{Why Consider Rangeland Sustainability?}

United States rangelands currently cover approximately 770 million acres and provide important commodity, amenity, and spiritual values. The country has lost more than 10 million acres of rangelands since 1982, primarily to development and cropland (16). Projections suggest that land available for livestock forage production will decrease over the next 50 years, with the actual rate depending upon environmental issues, government policies, and competing uses. Conversely, grazing land use for wildlife habitat, as well as wildlife-related human activities such as hunting, is predicted to increase during the same period (17).

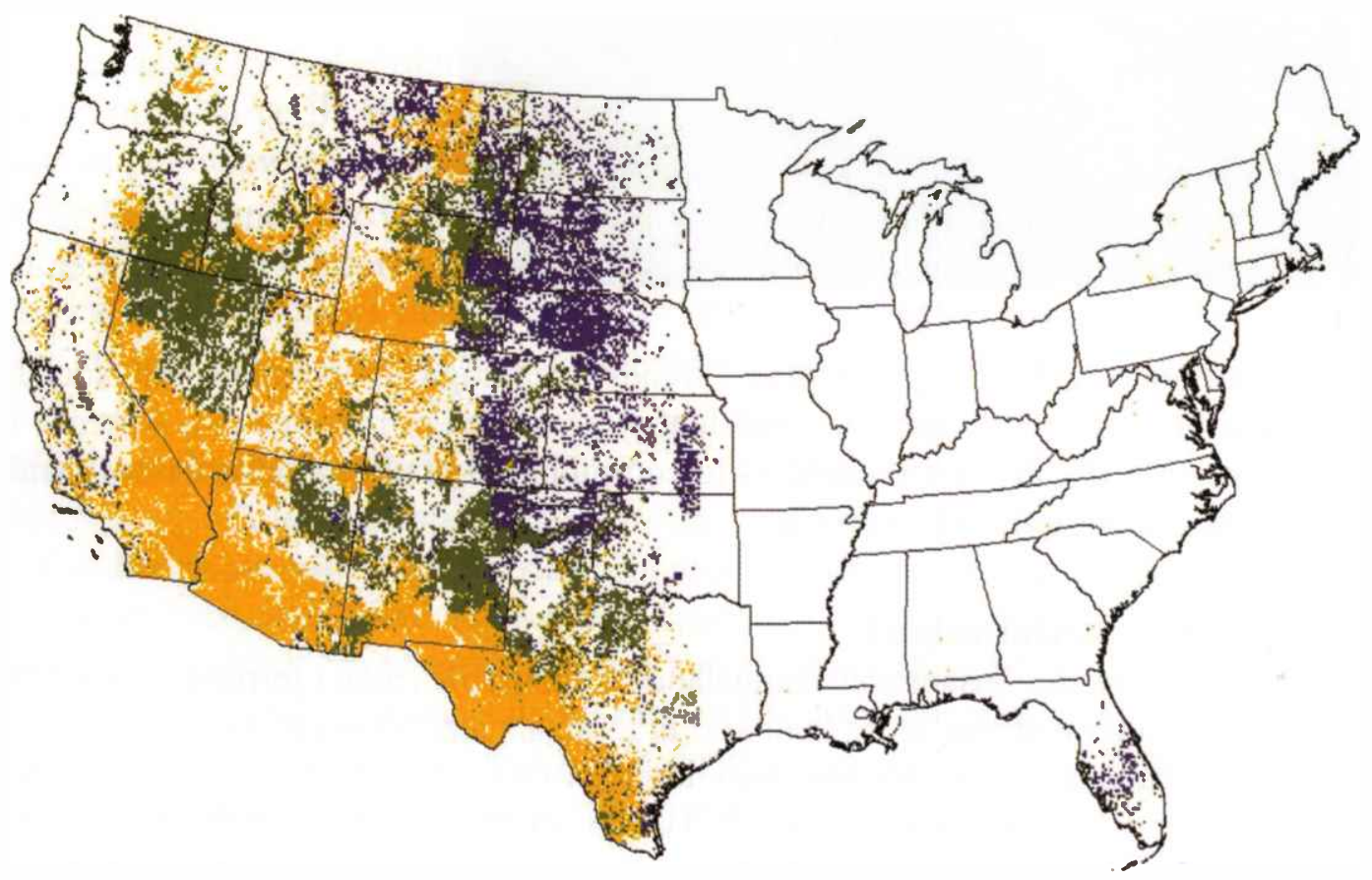

Rangeland ecosystems account for approximately one-third of the lands in the United States, including Great Plains grasslands, savannas in Texas and Florida, sagebrush steppe and shrublands in the Great Basin, Alaskan tundra, alpine meadows, wetlands, and Southwestern deserts. Map courtesy of USDA Forest Service showing grasslands (purple), shrublands (orange), and mixed shrub-steppe vegetation (green).

As competing demands contend for increasingly limited rangeland resources, consistent, comparable economic, social, and ecological data is necessary for informed decision-making regarding tradeoffs 
among goods and services derived from rangelands. Valuable products associated with grasslands, savannas, shrublands, alpine meadows, wetlands, and tundra include:

- Forage for domestic and wild grazing animals;

- Wildlife habitat;

- Water storage and filtration;

- Carbon sequestration to slow global warming;

- Recreation opportunities;

- Open space and viewsheds; and,

- A way of life for rangeland-dependent communities (3).

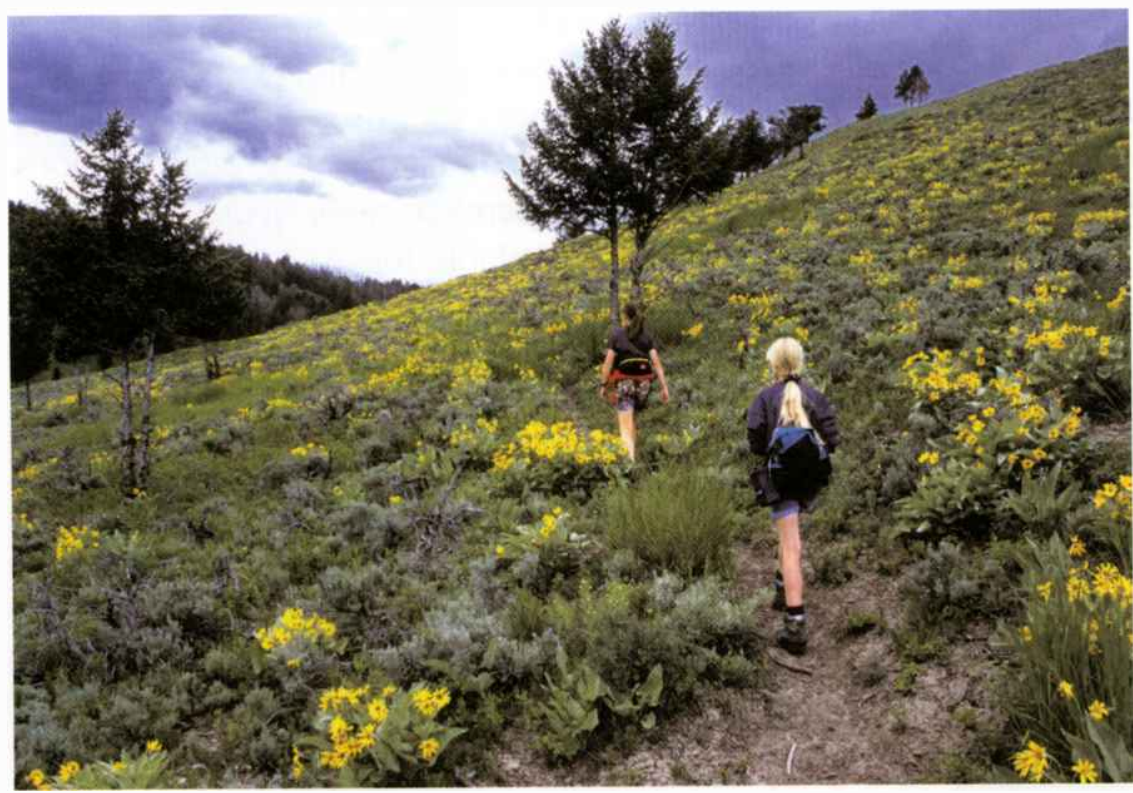

Diverse rangelands provide increasingly popular opportunities for outdoor recreation; photo courtesy National Park Service.

Despite the importance of this unique resource, trends in ecological, economic, and social components of rangeland sustainability currently are not consistently monitored or reported (1). Absence of such critical information makes it difficult for stakeholders to communicate about rangeland issues with each other, the general public, media, and policymakers (3).

\section{Are U.S. Rangelands Sustainable?}

To address this question, the Sustainable Rangelands Roundtable (SRR) formed in April 2001 as a collaborative partnership, now involving more than 100 individuals and 50 organizations. Participants include rangeland scientists and managers, ecologists, sociologists, economists, policy and legal experts, environmental advocates, and industry representatives (1). This paper summarizes SRR's preliminary assessment products, associated benefits, potential applications, challenges, and future plans. Operating procedures and processes utilized during development of SRR's framework for assessing progress toward social, ecological, and economic rangeland sustainability were described by Rowe and co-authors in 2002 (13).

Parity among economic, ecological, and social elements is a distinguishing characteristic of SRR's work (1). Sustainability may be visualized as a stool, with each aspect of sustainability representing a leg of the stool. If ecological, economic, or social factors are unequally included, the sustainability stool will become unbalanced.

Sustainable Rangelands Roundtable financial support has come from Colorado State University, USDA Forest Service, USDA Agricultural Research Service, USDI Bureau of Land Management, and 
USDI Geological Survey. However, SRR's dedicated participants volunteered the most significant contributions to criteria and indicator development, devoting expertise, time and effort. In addition to attending up to five, two-day meetings per year, participants assist with outreach and education efforts, serve on special working groups, and continue indicator work between meetings (3).

Through this dedication, SRR participants integrated social, economic, and ecological factors to form their criteria and indicator framework for assessing sustainable rangeland management at multiple spatial scales. Criteria are statements of conditions or processes that are goals of sustainable development, while indicators are repeated observations of natural and social phenomena that measure human well-being, the economy, and natural resource conditions to illustrate trends and changes (12). Criteria and indicators developed by SRR are summarized here and thoroughly detailed in SRR's First Approximation Report on Criteria and Indicators for Sustainable Rangelands, available at http://sustainablerangelands.cnr.colostate.edu/.

Collectively, SRR indicators determine trends in resource condition, management effects, economic outputs, and social values provided by rangelands. Specific benefits for rangeland managers and stakeholders include:

- Implementation of standardized periodic inventory, monitoring, and reporting on private and public rangelands;

- Improved coordination among local, regional, and national assessments;

- Provision of common frameworks for data collection and reporting to more clearly depict rangeland management performance and to minimize duplication in reporting;

- Enhanced interagency cooperation and collaboration;

- Identification of research needed to address indicator data gaps;

- Provision of a basis for stakeholder dialogue and better informed national policy deliberations;

- Justification of resource allocations for rangeland management and science; and,

- Expansion of public awareness and understanding of rangeland sustainability issues (3).

Although the SRR framework will enhance agency operations, SRR will not try to set policy. Instead, SRR's indicators will provide information to improve debates about rangeland management issues. While conclusions based upon indicators may be argued, SRR's indicators provide common ground for stakeholder dialogue, as well as consistent communication with the general public (3).

\section{Pieces of the Sustainability Puzzle}

Sustainable Rangelands Roundtable participants concluded that the sustainability puzzle has 64 pieces, or indicators, that can be assembled to describe progress toward sustainable rangeland management. These indicators are categorized under five overarching criteria: 1) conservation and maintenance of soil and water resources on rangelands, 2) conservation and maintenance of plant and animal resources on rangelands, 3) maintenance of productive capacity on rangelands, 4) maintenance and enhancement of multiple economic and social benefits to current and future generations, and 5) legal, institutional, and economic frameworks for rangeland conservation and management (1).

Conservation of soil and water resources on rangelands - Soils provide a medium for water capture, retention, and release (19), and soil erosion has contributed to human civilization declines during the past 7000 years (10). Additionally, rangelands' capacity to sustainably produce commodities and to satisfy society's expectations interacts with ongoing soil genesis, nutrient cycling, and energy flow (4). Soil and water also support primary production processes such as energy capture and flow. Therefore, soil and water indicators provide valuable information on rangeland sustainability status and associated human communities. Indicators under this criterion address (9):

- Soil erosion by water and/or wind

- Soil organic matter 
- Soil aggregate stability

- Bare ground

- Soil microbial activity

- Biodiversity of aquatic organisms

- Water quality

- Ground water systems

- Stream channel geometry

- Frequency and duration of no-flow periods in rangeland streams

SRR indicators address the importance of maintaining stream flows, channel geometry, and water quality and quantity; photo courtesy Kristie Maczko, Colorado State University.

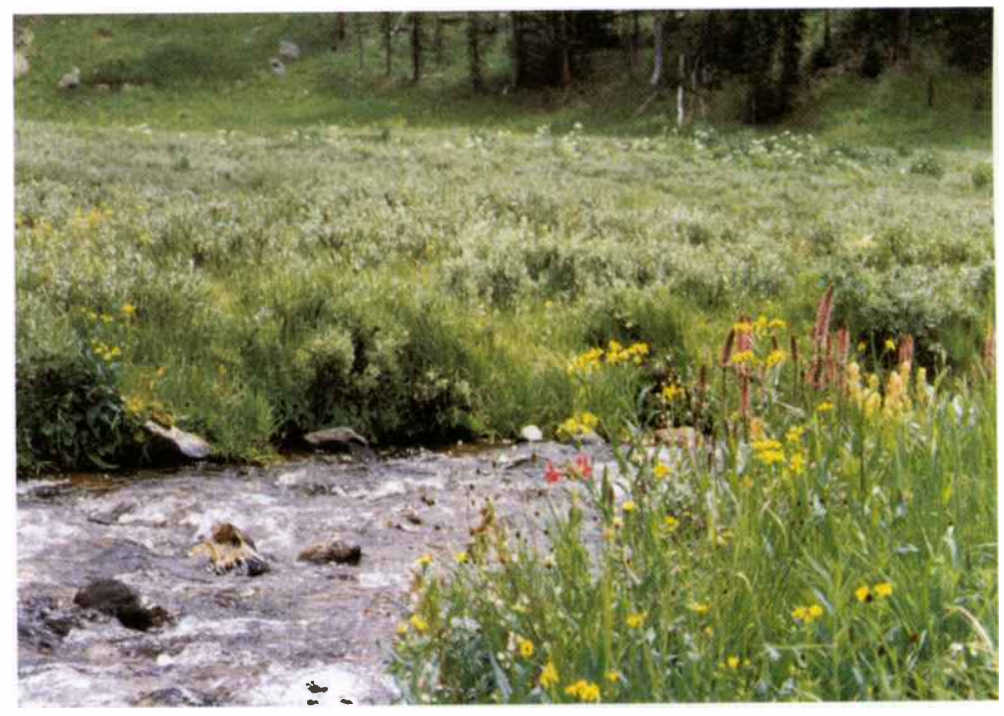

Conservation of plant and animal resources on rangelands - Rangelands' capacity to function, produce commodities, and satisfy societal values on a sustained basis is associated with internal ecological processes at multiple scales (4). Therefore, standardized assessment and monitoring methods and protocols are needed to describe structure and functional dynamics of plant and animal communities on U.S. rangelands. Sustainable Rangelands Roundtable participants identified ten indicators under this criterion (8):

- Extent of rangelands

- Rangeland area by vegetation type

- Number and extent of wetlands

- Fragmentation of rangelands

- Density of roads and human structures

- Natural fire regimes

- Condition of riparian systems

- Infestation by invasive plants

- Distribution of species and communities of concern

- Population status of rangeland-dependent species

Maintenance of productive capacity on rangelands - Stakeholders are well aware that rangelands provide current generations with many goods and services. Productivity is based on biophysical factors that annually yield plant biomass, reflecting climate, soil, and plant composition, as well as historic and current uses. Sustainable Rangelands Roundtable participants defined productive capacity to include forage-based products, such as livestock, as well as non-forage goods, such as wildlife habitat, open space, medicinal plants, and wood products. Six indicators under this criterion quantify (5): 
- Rangeland above-ground biomass

- Rangeland annual productivity

- Livestock numbers

- Acres of rangeland grazed by livestock

- Wildlife populations

- Annual removal of native hay and non-forage plant products

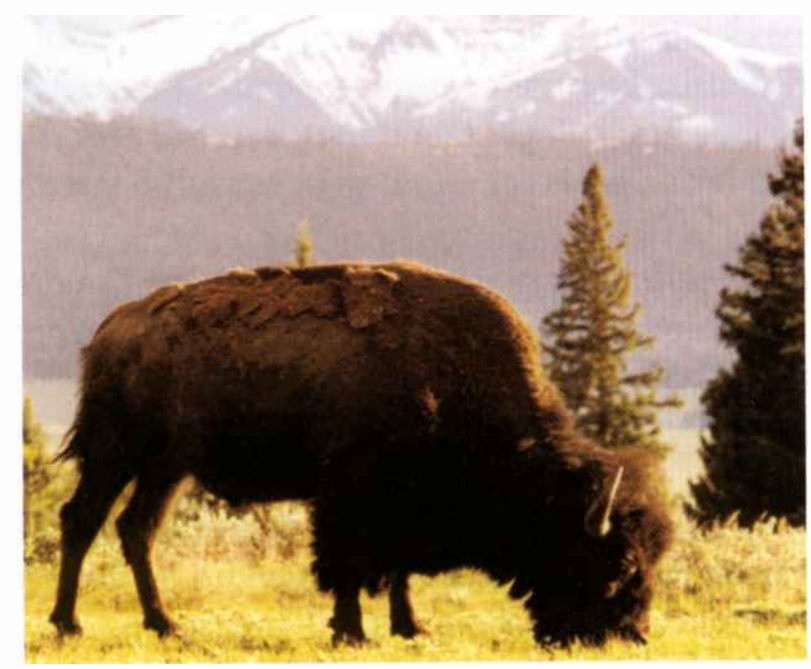

Grazing land use for wildlife habitat and wildlife-related human activities is projected to increase over the next 50 years; photo courtesy Kristie Maczko; Colorado State University

Maintenance of productive capacity implies that future generations also will be able to obtain their desired mix of market and non-market goods from rangelands. Identifying and monitoring production of goods and services over long time frames requires multi-scale measurement capability, spanning the ecological site to the eco-region. These spatial and temporal scale issues provide additional challenges for SRR and land managers in general.

Forty-three percent of U.S. rangeland ecosystems are monitored and managed by federal government agencies; photo courtesy National Cattlemen's Beef Association.

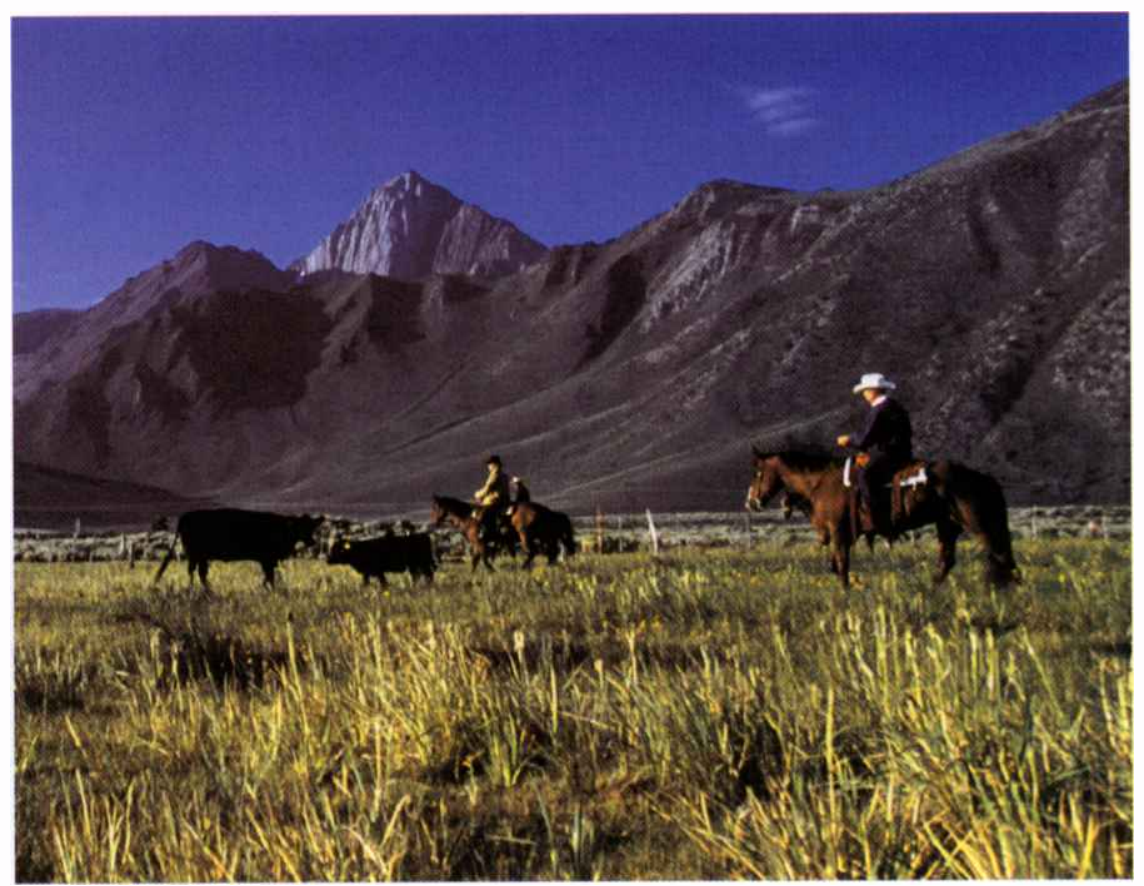




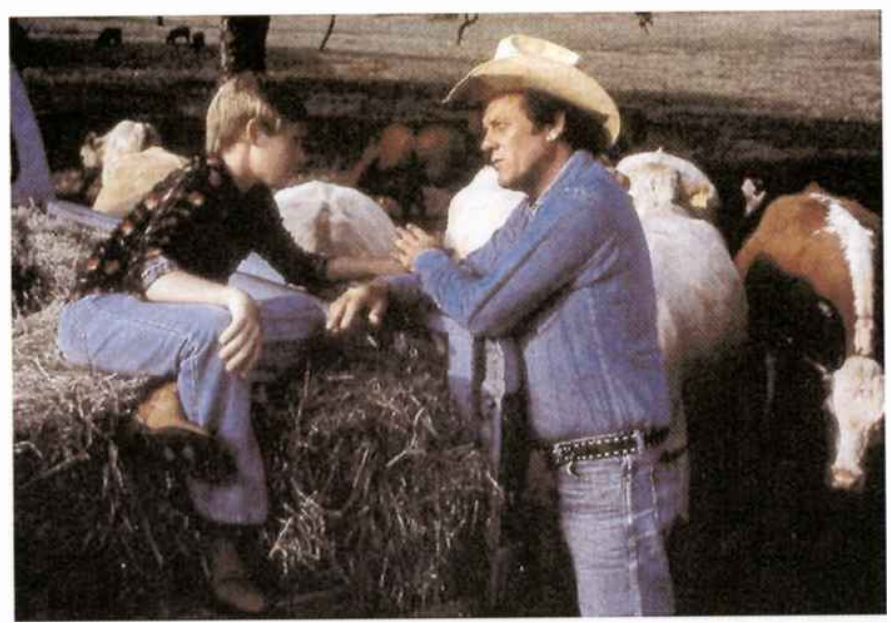

Indicator-based monitoring and reporting will contribute toward a future in which U.S. rangelands supply current generations with their desired mix of goods and services without compromising the ability of future generations to meet their needs; photo courtesy Tom Field, Colorado State University.

Maintenance and enhancement of economic and social benefits - Social systems are the least studied component of rangeland science and management (18), and few range-specific measures of social and economic attributes exist (14). Monitoring social components of sustainability becomes more important as development pressure on rangelands grows, making clear communications among diverse stakeholders and the general public more critical (3).

Socioeconomic indicators developed by SRR participants measure society's values and reflect allocation of scarce economic resources. Indicators under this criterion illustrate how changes in ecological, legal, and political systems are manifested in economic systems. Three groupings of indicators offer a more complete view of rangelands and rangeland use within the larger social and economic context:

- "National Economic Benefits" indicators define the types of products derived from rangelands;

- "Community Well-Being and Capacity" indicators measure community health and welfare in rangeland-dominated areas; and,

- "Community Level Explanatory Indicators That Might Be Relevant to Sustainability" attempt to quantify how communities affect rangelands (15).

In total, 28 indicators focus on demographic change in rangeland-dependent areas, community wellbeing, structure of economic activity, structure of government and social services, social structure quality,

Rangeland amenity values such as scenery, biodiversity, and recreation compete with production of commodities like forage and wild game (2); photo courtesy Kristie Maczko, Colorado State University.

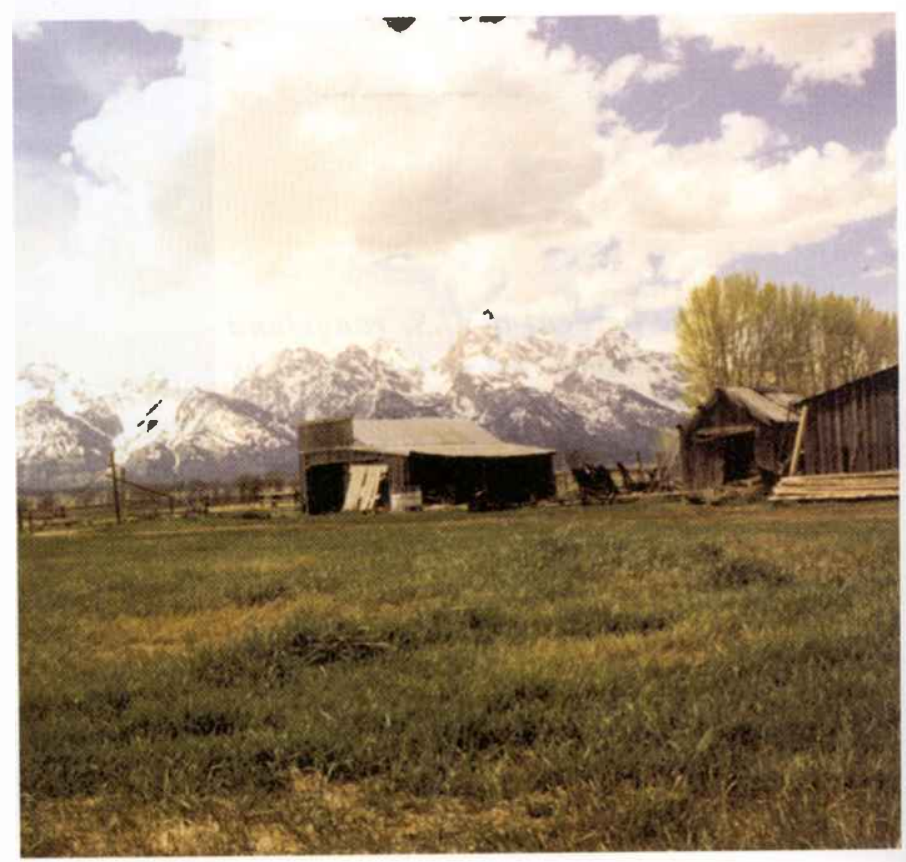


patterns of land tenure, and use/production related issues. Traditional forage-based uses and nontraditional, non-consumptive uses, such as recreation, are addressed (15).

Socio-economic indicators are broad in scope, thus questions arise related to landowner priorities and data aggregation. Issues relevant to individual, private rangeland owners may not be relevant at broader regional and national levels, and aggregation of certain data sets may alter analyses outcomes. As a result, new research protocols may be necessary to clarify relationships among existing socioeconomic data sets and to resolve aggregation issues; SRR criteria and indicators will allow experts to address these questions (14).

Legal and institutional frameworks for sustainable rangeland management - Indicators within SRR's final criterion seek to measure the extent to which U.S. laws, regulations, guidelines, and policy frameworks support conservation and sustainable management of rangelands. Issues of equity, economic efficacy, cultural traditions, legal rights and obligations, and advancing management theories and skills greatly influence long-term rangeland sustainability. Ten indicators assess (6):

- Land law and property rights

- Institutions and organizations

- Economic policies and practices

- Public information and participation

- Professional education and technical assistance

- Land management

- Planning, assessment, and policy review

- Protection of special values

- Measuring and monitoring

- Research and development

These indicators accentuate the importance of local-level data for regional and national assessments, and require collection and integration of county, state or regional, and national information. While data exist to describe institutions, mechanisms, and capacities affecting rangelands, lack of information about how a given institution actually impacts rangeland management on the ground is problematic (11). In many cases, SRR participants chose subjective evaluations rather than quantitative methods to assess these indicators (6).

\section{Criteria and Indicators to Piece the Puzzle Together}

Our knowledge continues to increase about interactions among natural disturbances, such as drought and fire, as well as associated effects on rangeland ecosystems and communities. Land management policies are periodically reviewed and revised in accordance with evolving facts. However, no adequate, standardized monitoring system or suite of data presently exists to provide governments, landowners, and land managers with information necessary to assess and deal with such rangeland disturbances at multiple scales (3).

Collaborative efforts involving affected stakeholders typically foster sound decision-making and lead to implementation of agreed-upon tactics. Contending with potentially catastrophic events including drought and fire is most effective when public officials coordinate with private landowners and organizations. Additionally, scarce resources are allocated more efficiently when decision-makers thoroughly understand ecological and socio-economic impacts of their choices. Indicators identified by SRR fill a significant gap to inform decisions involving natural phenomena such as drought and fire (3).

Using indicators to assess effects of drought - Drought impacts rangeland conditions and management by decreasing forage availability for wildlife and livestock, as well as by causing native plants to decline, soil to erode, and water supplies to dry up. Drought's effects on rangeland-dependent communities have been studied and documented; however, drought indices do not always provide enough information to make decisions. The SRR monitoring framework helps address this problem by providing decision-makers 
with trend data in areas such as primary productivity, rangeland aboveground biomass, and number of livestock on rangeland (3).

Agricultural systems illustrate linkages between ecological conditions and maintenance of productive capacity on rangelands. Productive capacity encompasses more than livestock; ranchers profit from wildlife, hay, recreation, and other products, all of which are negatively affected by drought. Indicators to track production-related agricultural impacts of drought include (3):

- Rangeland aboveground biomass

- Rangeland annual productivity

- Number of domestic livestock on rangeland

- Wildlife numbers

- Annual removal of native hay

- Area of infestation of invasive weeds

Drought also affects rangeland productive capacity through declines in the soil profile and surface and subsurface water supplies. Extended hydrological droughts damage natural ecosystems, especially near wetlands and ephemeral streams, and loss of vegetation may make soils more susceptible to wind erosion. Indicators that measure responses to hydrological drought include (3):

- Change in area of bare ground

- Changes in groundwater systems

- Change in stream no-flow periods

- Condition of riparian systems and wetlands

Ecological impacts of drought also are closely associated with economic and social aspects of rangeland sustainability, and stakeholders recognize drought's cascading effects on rangeland-dependent counties and towns. Goods and services including fresh water and forage depend upon weather; therefore, inadequate rainfall impacts production of such commodities. Indicators that quantify drought's socio-economic impacts include (3):

- Value of forage harvested

- Employment diversity

- Land tenure, use, and ownership patterns

- Sources and amounts of community income

- Return on rangeland investments

Additional research is needed to clarify relationships among indicators. While some excellent data sources currently are available, others require further development. For example, changes in primary productivity - the rate at which plant biomass accumulates during a growing season - offers a graphic depiction of drought's effects upon rangelands. One of the best primary productivity metrics is the Normalized Difference Vegetation Index (NDVI), a readily available, remotely sensed value. This measure has been used for many years, and data can be aggregated from the management unit to the national level (3).

Similarly, tracking trends in livestock herd size provides useful information. Landowner privacy concerns and management unit level sampling intensity issues partially preclude data collection on livestock that spend some of the year on pastures and rangelands. However, in drought years, forage shortages may result in livestock sale; almost normal weaning weights can be reached by adjusting stocking rate to forage supply. Tracking regional trends in livestock herd sizes through SRR indicators can provide valuable data to corroborate management actions to de-stock drought-stricken rangeland (3).

In contrast to available NDVI and regional herd information, adequate data do not exist for total aboveground biomass; green vegetation, dead material from years past, and litter. Although dead material is low in nutrients and palatability, grazing animals consume it when forage is limited. Aboveground biomass is a useful SRR indicator for monitoring drought effects. Since this information is not currently col- 
lected, SRR will encourage development of protocols and methodologies for monitoring aboveground biomass (3).

Using indicators to assess effects of fire - Indicators identified by SRR also track natural fire regime trends and impacts. Human activities have shifted the season, intensity, and frequency of fire from historic patterns. Fire monitoring will improve understanding of interactions among fire, grazing, non-native plants, soils, and species of concern, and associated impacts upon rangeland ecosystems and their processes (3).

Fires are inherently local events, spanning political, administrative, and land use boundaries. Local landscapes are characterized by different plant communities and land uses, tying fire data to local conditions. However, fire information must be aggregated from management units to broader scales to be useful for agencies and scientists. Many SRR indicators are applicable at multiple scales, and ideally suited for such assessments. Indicator-based monitoring also emphasizes standardization of data collection programs across fire monitoring agencies and organizations. Indicators to assess fire effects on rangeland use include (3):

- Rangeland annual productivity

- Area of infestation by invasive weeds

- Population status of rangeland-dependent species

- Area of rangeland with accelerated erosion

- Change in extent of bare ground

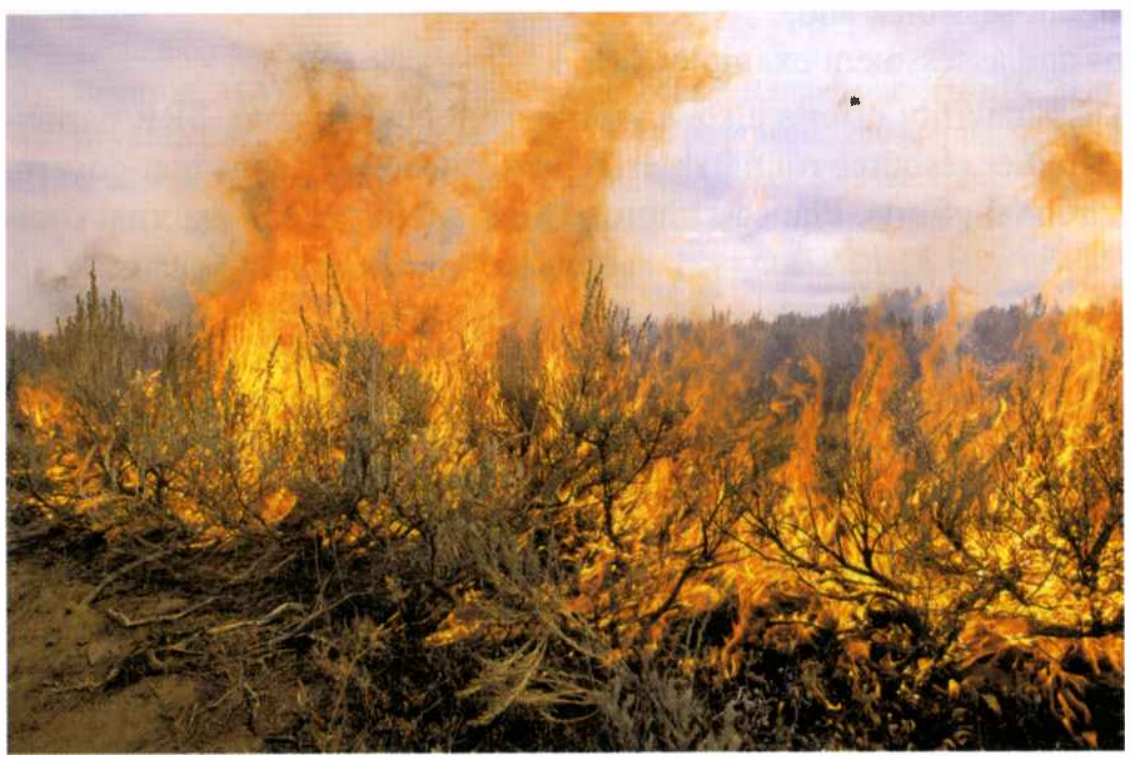

Disturbances including erosion, fire, and establishment of invasive plant populations impact rangeland sustainability; photo courtesy USDA Agricultural Research Service.

Currently some fire information is available, while protocols for additional data sets must be developed. Limited data exist on acres burned at regional and national levels, but data collection methods and procedures are not standardized. Also, data about fire location and seasonality are largely unavailable (3).

New research protocols are needed for measuring how spatial and seasonal distribution of fire vary across land management categories. Remote sensing has high potential for monitoring fire extent and spatial distribution because of data applicability at multiple spatial scales. The SRR will advocate development of monitoring protocols to track fire area, spatial distribution, and seasonality across administrative and political boundaries. Whether looking at fire patterns in a county, state, region, or for all U.S. rangelands, a consistent set of accepted indicators will make monitoring easier and more useful for researchers and land managers (3). 


\section{SRR Plans and Priorities}

The Sustainable Rangeland Roundtable's long-term goals are tightly linked to participants' vision of a future in which "U.S. rangelands provide a desired mix of social, economic, and ecological benefits to current and future generations; and criteria and indicators for monitoring and assessing the economic, social, and ecological sustainability of rangelands are widely accepted and used." In the short-term, SRR goals and objectives emphasize:

- Criteria and indicator implementation and refinement;

- Data set identification and analysis;

- Communication planning, education and outreach efforts;

- Interagency and organizational coordination; and,

- Categorization of research needs, including recommended protocols (1).

The United States' political process and democratic structure ensure that programs strongly and vocally supported by resource stakeholders will garner similar support from politicians and appointees representing these groups. Therefore, increased awareness of and support for SRR initiatives is critical for continued progress. Communication, education, and outreach efforts will seek stakeholder input and promote sustainable rangelands indicator acceptance and use. Highlights from SRR's strategic plan include:

- Communication plan implementation;

- Development of educational materials and presentations;

- Stakeholder focus groups and comment sessions; and,

- Creation of indicator interpretations and assessment examples (3).

Interaction with parallel rangeland sustainability efforts also is a primary focus. To date, SRR participants have reviewed indicator products of other resource roundtables, federal agencies, states, non-governmental organizations (NGOs), and international efforts. Plans to improve SRR's internal and external coordination include:

- Establishing formal interagency agreements to define key roles and responsibilities;

- Convening a workshop to identify data sets, sources, and gaps; and,

- Improving communication with local and regional assessment programs to distinguish on-the-ground management criteria and indicator applications (3).

Additionally, SRR will promote research to develop protocols that will address data gaps associated with individual indicator measurement and analysis. Broader priority research topics will emphasize interrelationships among ecological, economic, and social indicators. Potential projects include:

- Scientific evaluations of indicators and reliability of their relationship to the criteria;

- Benefit-cost analyses on indicator use; and,

- Assessments of criteria and indicator applications and stakeholder acceptance (3).

Achievement of SRR's goals and objectives depends upon stable and adequate funding and resources, which is closely tied to stakeholder support. Associated challenges that must be addressed for SRR's contimted progress include:

- Database management, accuracy, consistency, and integration issues;

- Selection of operational definitions of forests and rangelands; and,

- Establishment of research protocols to deal with scale issues and interactions among human community and economic indicators (1).

\section{Sustainability for the Future}

The Sustainable Rangelands Roundtable and related sustainability efforts invite innovation and experimentation. Federal land management agency leadership has pledged to broaden and deepen their commit- 
ment to sustainability (7). Associated opportunities to develop cooperative research protocols and partnerships, expand information exchange, and employ standardized, periodic reporting for rangeland assessments will grow with sustainable resource management.

Sustainable Rangelands Roundtable participants will continue to fulfill their mission to "promote social, ecological, and economic sustainability of rangelands through the development and widespread use of criteria and indicators for rangeland assessments," and to provide "a forum for dialogue on sustainability of rangelands." Roundtable conveners and participants look forward to engaging all interested stakeholders in the SRR process.

About the Authors: Kristie Maczko is a Project Analyst with the Department of Forest, Rangeland, and Watershed Stewardship, Colorado State University, Fort Collins, Colorado. Larry Bryant is the Assistant Director for Vegetation Management and Planning, USDA Forest Service, Washington D.C. Dennis Thompson is the Range and Grazing Lands Ecologist, Natural Resource Conservation Service, Washington D.C. Steven Borchard is the Deputy Group Manager for Rangeland, Soil, Water \& Air, Bureau of Land Management, Washington D.C.

\section{References}

1) Bartlett, E.T., K.A. Maczko, and J.E. Mitchell. 2003. Ecological, economic, and social indicators: assessing rangeland sustainability, p. 1897-1908. In: Allsopp, N. A.R. Palmer, S.J. Milton, K.P. Kirkman, G.I.H. Kerley, and C.R. Hurt (eds.) Proc. VII ${ }^{\text {th }}$ Int. Rangeland Congress, $26^{\text {th }}$ July $-1^{\text {st }}$ August 2003, Durban, South Africa. Document Transformation Technologies, Irene, South Africa.

2) Brunson, M.W. 2003. Rangelands and Society. Rangelands 25(6):16-21.

3) Bryant, L.D., K.A. Maczko, and D.W. Thompson. 2004. Rangeland sustainability: integrating social, ecological, and economic indicators. In: Peterson, J.W. (ed.) Proc. $2^{\text {nd }}$ Nat. Conf. on Grazing Lands, December 7-10, 2003. Nashville, Tenn. Grazing Lands Conservation Initiative. Bryan, Texas. [in press]

4) Committee on Rangeland Classification. 1994. Rangeland health: new methods to classify, inventory and monitor rangelands. Nat. Acad. Press. Washington, D.C.

5) Evans, G.R., B.H. Allen-Diaz, B.A. Bobowski, R.D. Child, R.V. Loper, J.E. Mitchell, T.B. Reuwsaat, D.W. Thompson, and G.R. Welling. 2003. Indicators for maintenance of productive capacity on rangelands, p. 142-170. In Sustainable Rangelands Roundtable (ed.) Criteria and indicators for sustainable rangelands: a first approximation report. Available at http://SustainableRangelands.cnr.colostate.edu. Colorado State Univ. Fort Collins, Colo.

6) Hamilton, S.F., T.D. Lustig, T.C. Roberts, Jr., S.W. Albrecht, J. Campbell, K.E. Nelson, B. Czech, and K. Kuhlman. 2003. Indicators of legal, institutional, and economic framework for rangeland conservation and sustainable management, p. 200-244. In: Sustainable Rangelands Roundtable (ed.) Criteria and indicators for sustainable rangelands: a first approximation report. Available at http://SustainableRangelands.cnr.colostate.edu. Colorado State Univ. Fort Collins, Colo.

7) Holtrop, J. 2002. Welcome address. Final Review Workshop, Nat. Rep. on Sustainable Forests, November $21,2002$. Washington D.C.

8) Joyce, L., W. Fox, P. Geissler, R. Heitschmidt, L. Hidinger, D. Patten, J. Spence, L. Strong, R. Unnasch, and R. Washington-Allen. 2003. Indicators for conservation and maintenance of plant and animal resources on rangelands, $\mathrm{pp}$. 56-141. In: Sustainable Rangelands Roundtable (ed.) Criteria and indicators for sustainable rangelands: a first approximation report. Available at http://SustainableRangelands.cnr.colostate.edu. Colorado State Univ. Fort Collins, Colo.

9) Karl, M. G., D. A. Pyke, P.T. Tueller, G.E. Schuman, M.R. Vinson, J.L. Fogg, R.W. Shafer, S.J. Borchard, W.G. Yipsilantis, and R.H. Barrett, Jr. 2003. Indicators for soil and water conservation on rangelands, pp. 20-55. In: Sustainable Rangelands Roundtable (ed.) Criteria and indicators for sustainable rangelands: a first approximation report. Available at http://SustainableRangelands.cnr.colostate.edu. Colorado State Univ. Fort Collins, Colo.

10) Lowdermilk, W.C. 1953. Conquest of the Land through 7,000 years. USDA NRCS Agr. Info. Bull. No. 99. Washington D.C.

11) Lustig, T.D. 2002. Status of institutional criteria and indicators, p. 59-62. In: Bartlett E.T. and J.E. Mitchell (eds.) Sustainable rangeland management: status of a roundtable to determine criteria and indicators, a work in progress. Proc. Sustainable Rangelands Roundtable symposium at Soc. Range Manage. Ann. Meeting, Kansas City. Colorado State Univ. Fort Collins, Colo. 
12) National Research Council Board on Sustainable Development. 1999. Our common journey: a transition toward sustainability. Nat. Acad. Press. Washington DC.

13) Rowe, H.I., K. Maczko, E.T. Bartlett, and J. Mitchell. 2002. Sustainable Rangelands Roundtable. Rangelands 24(6):1-3.

14) Tanaka, J.A. and L.A. Torell. 2002. Status of economic criteria and indicators for the sustainable rangelands roundtable, p. 51-53. In: Bartlett E.T. and J.E. Mitchell (eds.) Sustainable rangeland management: status of a roundtable to determine criteria and indicators, a work in progress. Proc. Sustainable Rangelands Roundtable symposium at Soc. Range Manage. Ann. Meeting, Kansas City. Colorado State Univ. Fort Collins, Colo.

15) Tanaka, J., L.A. Torell, L.V. Swanson, M. Brunson, D. McCollum, and H.T. Heintz, Jr. 2003. Indicators for maintenance and enhancement of multiple economic and social benefits to current and future generations, p 171-199. In: Sustainable Rangelands Roundtable (ed.) Criteria and indicators for sustainable rangelands: a first approximation report. Available at http://SustainableRangelands.cnr.colostate.edu. Colorado State Univ., Fort Collins, Colo.

16) USDA Natural Resources Conservation Service. 2000. Summary Report 1997 National Resources Inventory. USDA NRCS. Washington, D.C.

17) Van Tassell, L.W., E.T. Bartlett, and J.E. Mitchell. 2001. Projected use of grazed forages in the United States: 2000 to 2050. USDA For. Serv. Rocky Mountain Res. Sta. Gen. Tech. Rep. RMRS-GTR-82. Fort Collins, Colo.

18) Vavra, M. 1995. Rangeland research: strategies for providing sustainability and stewardship to the rangelands of America and the world. Rangelands. 17:200-214.

19) Whisenant, S.G. 1999. Repairing damaged wildlands: a process-oriented, landscape-scale approach. Cambridge Univ. Press. United Kingdom. 